\title{
Performance of Glazing Materials for Atrium in Hot \& Humid Climate
}

\author{
Suhendri ${ }^{1}$, Wahri Sunanda ${ }^{2}$ and Rachmawan Budiarto ${ }^{3}$ \\ ${ }^{1}$ Institut Teknologi Bandung, Architecture Program, Bandung, Indonesia \\ ${ }^{2}$ Universitas Bangka Belitung, Engineering Physics Department, Pangkalpinang, Indonesia \\ ${ }^{3}$ Universitas Gadjah Mada, Engineering Physics Department, Yogyakarta, Indonesia
}

\begin{abstract}
One comfort issue that considered to be the most important is thermal comfort. Air temperature is the most influential factor, and it is related to solar radiation and building's glazing. Besides thermal comfort, glazing is also needed to provide daylighting. Therefore, due to its relation to thermal comfort and daylighting, the glazing materials selection is crucial. Hence, by focusing on atrium in hot and humid climate, this study is aimed to examine a sufficient material with good thermal and daylighting performance. The results show that argon filled glazing is the most suitable material for atrium glazing in hot and humid climate. Argon filled glass has lowest U-value and total solar transmission than any other glazing materials simulated, but its light transmission is not too low so the daylight delivered still adequate to the standard. Accordingly, U-value, solar heat gain coefficient, and light transmission coefficient are concluded as the determinant factor in selecting glazing material.
\end{abstract}

\section{Introduction}

One of comfort issues that considered being the most important is thermal comfort. The annual survey performed in the US, however, shows that $30 \%$ of building occupants are dissatisfied with indoor temperature and $80 \%$ of complaints about buildings relate to thermal comfort [1]. Even more in hot and humid climate, thermal comfort is a common issue. Air temperature is the most influential factor, and it is related to solar radiation penetrate into a building through building's glazing [2]. Thus, solar radiation, especially in hot and humid climate, has a relation to the thermal comfort inside the building and cooling load of building [3]. Therefore, windows and other openings in building envelope play important role to provide thermal [4].

In addition to thermal comfort issue, openings in building envelope are necessary to provide daylighting. Daylighting is a natural lighting source which provides visual comfort and the delightful of indoor environment, and it has been a primary source of lighting in buildings [5]. Daylighting also has a significant effect on occupant's health as well as occupant's productivity [6]. In brief, light and heat as elements of solar radiation have been important variables that affect the occupant's comfort [7]. Therefore, the design of glazing area of a building and its materials need to reduce solar gains and provide adequate levels of daylight as well [8].

The strategies to deliver daylighting through glazing area in building envelope have been practiced since the beginning of architecture itself. There are two methods to deliver daylight into building, by side-lighting and top-lighting. Top-lighting as one of the strategies did not get attention to be researched as much as side-lighting strategy. Focusing on top-lighting method through atrium in hot and humid climate, this study is aimed to examine a sufficient material with good thermal and daylighting performance. Thus, the study needs to compare different glazing technologies. From the comparison, this study reports the general principles in selecting glazing material for atrium in hot and humid climate.

\subsection{Thermal Comfort}

Thermal comfort is defined as the condition of mind that expresses satisfaction with the thermal environment [9]. In general, there are two categories of variables that related to thermal comfort, environmental variables, and personal variables. Environmental variable consists of air temperature, mean radiant temperature, air velocity, and relative humidity. The personal variables are metabolic rate due to activity level, clothing insulation [10].

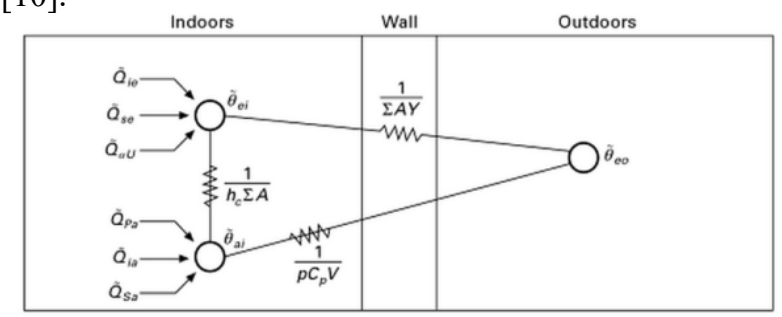

Fig. 1. Nodal network diagram under transient environmental conditions [11]. 
The relation between indoor air temperature, and thus thermal comfort, to outdoor condition is described adequately using nodal network diagram as shown by Figure 1. The diagram uses three temperature nodes, represent three hypothetical temperatures that interact each other by transferring heat.

- Outdoors condition is represented by sol-air temperature $\left(\theta_{\mathrm{eo}}\right)$. It is affected by shortwave radiation, longwave radiation, and convective heat exchanges.

- Indoor condition is represented by two nodes:

- Environmental temperature, affected by conductive gains through the fabric, internal gains, and glazing solar gains.

- Mean air temperature, affected by plant load (mechanical heating/cooling), convective internal gains, and glazing solar gains.

Nodal diagram network gives better understanding on the role of solar radiation in determining indoor conditions. Yet, solar radiation is an important feature in lighting design as explained in the Daylighting Section below. In this manner solar radiation is recognised to be a parameter that is needed and avoided at the same time.

\subsection{Daylighting}

Visual comfort is a multidimensional subject, and thus not sufficient to use only illumination levels for its evaluation. British Standard has established daylight factor and average daylight factor as a measurement in daylighting. Daylight factor, as mentioned in BS 6100$7: 2008$, is ratio of illuminance at a point on a given plane due to light received from a sky of known or assumed luminance distribution, to illuminance on a horizontal plane due to an unobstructed hemisphere of this sky. While average daylight factor is defined as ratio of total daylight flux incident on a reference area to total area of reference area, expressed as a percentage of outdoor illuminance on a horizontal plane due to an unobstructed hemisphere of sky of assumed or known luminance distribution [12].

Illuminance and daylight factor is controlled by glazing design. The chosen material for glazing plays an important role in delivering good daylighting. With two parameters, daylight factor and illuminance, performance of the glazing materials are compared. British Standard gives a minimum daylight factor requirement for general building at least 2\% [12]. Meanwhile, the recommended illuminance levels needed for atrium is minimum 50-200 [13].

\section{Methodology}

The case study building is Marina Mandarin Hotel in Singapore. Its location is on the north side of Marina Bay. The architect of the building is John Portman \& Associates. Marina Mandarin is a 5-star hotel located in Marina Bay, and is part of the Marina Square mixed-use complex. Total area of the Marina Square mixed-use complex is 4 million square foot, including three convention hotels, a retail mall, and an office building surrounded by plazas and gardens [14].

One of the main features of the hotel structure is its magnificent atrium. Glazing material of the atrium is clear glass. However, due to Singapore's hot climate, solar heat still penetrates through the atrium and the clear glass cannot perform well in such condition. It makes intense heat gain to the interior [15]. The suitable material for the building is examined by comparing the performance of original glazing material with other materials.

Singapore itself is located in tropical zone, with warm humid climate classification. Average maximum temperature in Singapore is $32.18^{\circ} \mathrm{C}$ and its average minimum temperature is $23.27^{\circ} \mathrm{C}$. Singapore has average maximum relative humidity of $80.67 \%$ and average minimum relative humidity of $72.92 \%$. The main problem in this type of climatic zone is overheating. The overheating is provoked by high humidity, restricting the evaporation potential. The diurnal temperature variation is small. The primary concern in Singapore's climate is high solar altitude and radiation. Therefore, shading devise becomes a meaningful part for the building.
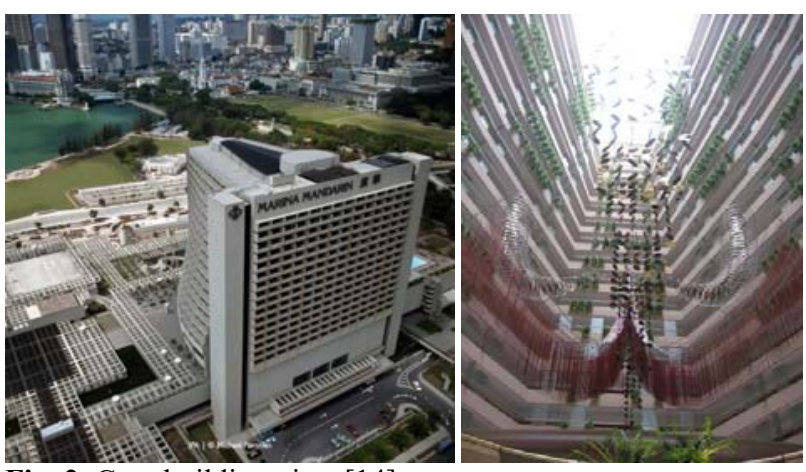

Fig. 2. Case building view [14].

Table 1. Properties of Glazing Technologies Used in the Simulation.(Source: [4])

\begin{tabular}{|c|c|c|c|c|}
\hline & $\begin{array}{l}\text { Solar } \\
\text { transmis- } \\
\text { sion }\end{array}$ & \begin{tabular}{|l|} 
Direct \\
solar \\
transmis- \\
sion
\end{tabular} & \begin{tabular}{|l} 
Light \\
transmis- \\
sion
\end{tabular} & $\begin{array}{c}\text { U- } \\
\text { value }\end{array}$ \\
\hline \multicolumn{5}{|c|}{ 1. Multilayer glazing } \\
\hline $\begin{array}{l}\text { Single Clear } \\
\text { Glazing }\end{array}$ & 0.810 & 0.775 & 0.881 & 6.121 \\
\hline $\begin{array}{l}\text { Double Clear } \\
\text { Glazing }\end{array}$ & 0.693 & 0.604 & 0.781 & 3.157 \\
\hline $\begin{array}{l}\text { Triple Clear } \\
\text { Glazing }\end{array}$ & 0.675 & 0.595 & 0.738 & 2.166 \\
\hline \multicolumn{5}{|c|}{ 2. Low-emittance glass } \\
\hline $\begin{array}{l}\text { Single Low-e } \\
\text { Glass }\end{array}$ & 0.710 & 0.680 & 0.811 & 4.233 \\
\hline $\begin{array}{l}\text { Double Low-e } \\
\text { Glass }\end{array}$ & 0.595 & 0.538 & 0.769 & 2.440 \\
\hline \multicolumn{5}{|c|}{ 3. Electrochromic glass } \\
\hline $\begin{array}{l}\text { Double } \\
\text { Electrochromic } \\
\text { Glass }\end{array}$ & 0.638 & 0.545 & 0.727 & 1.772 \\
\hline \multicolumn{5}{|l|}{ 4. Gas-filled glass } \\
\hline $\begin{array}{l}\text { Double Argon- } \\
\text { Filled Glass }\end{array}$ & 0.564 & 0.745 & 0.745 & 1.499 \\
\hline
\end{tabular}


In order to achieve the aim and objectives, the study employs two phases or steps. First of all, some glazing technologies that are usually used for glazing will be simulated using DesignBuilder software. Then, comparison is done to the simulation result. The technologies are, multilayer glazing, low-e glass, glass filled with absorbing gases, and electrochromic glass. Secondly, the parameters in selecting the glazing technologies for atrium in building method are derived from the simulation results (Table 1).

\section{Results \& Discussion}

\subsection{Multilayer Glazing}

\subsubsection{Analysis of Thermal Environment}

Performance of the multilayer glazing is observed by using temperature in the atrium hall below the glazing. There are three temperatures to be compared, air, radiant, and operative temperature. The comparison can be seen in Figure 1-3. From the graph, it can be seen that all of the glazing still can reduce the outside temperature. However, it also shows that the more glazing layer causes warmer temperature. It indicates that adding more glazing layer perhaps not an appropriate strategy for atrium in hot and humid climate.

Supporting evidence for the findings in Figure 4 can be explained by using the comparison of glazing heat losses data. From the data shown in Figure 4, heat losses from the atrium glazing are getting lower, reciprocal to the increasing number of glazing layer. It is because every glazing layer added to the glazing, reduces the Uvalue of the glass. Thus, heat transfer occurs in a lower rate. Hence, there is more heat trapped and it increases the temperature.

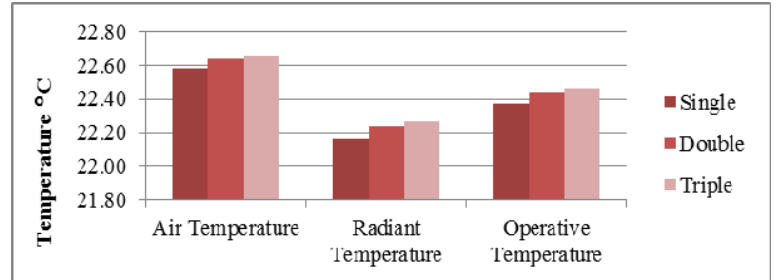

Fig. 3. Comparison of temperatures resulted from multilayer clear glass.

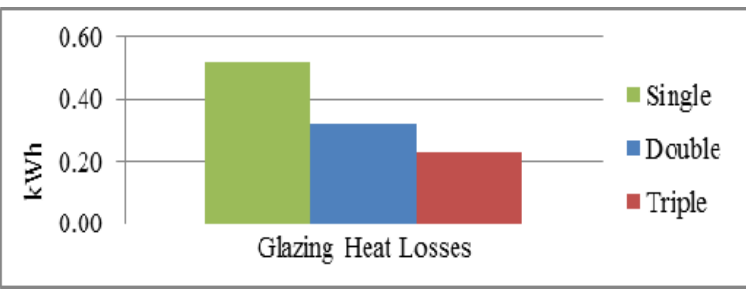

Fig. 4. Heat losses comparison of multilayer clear glass.

\subsubsection{Analysis of Daylighting}

By using the contour images from DesignBuilder, daylighting in the atrium below the glazing. Figure 5 shows the results comparison. According to illuminance minimum requirement for atrium building, the light should be between 50-200 lux. From the figure it can be seen that all of the three glazing materials deliver appropriate light. Generally, single clear glazing gives brighter daylight, although it is not the most uniform daylight distribution. It is due to light transmission of each glazing materials. More glazing layer means less light transmitted. Hence, single glazing passes more light

Overall, triple glazing has the lowest average daylight factor. However the values are quite similar, so the distribution of the light is the key to determine the preferred glazing. From Figure 5, it can be noticed that double glazing performs a better light distribution. There is also no significant glare for double glazing material.
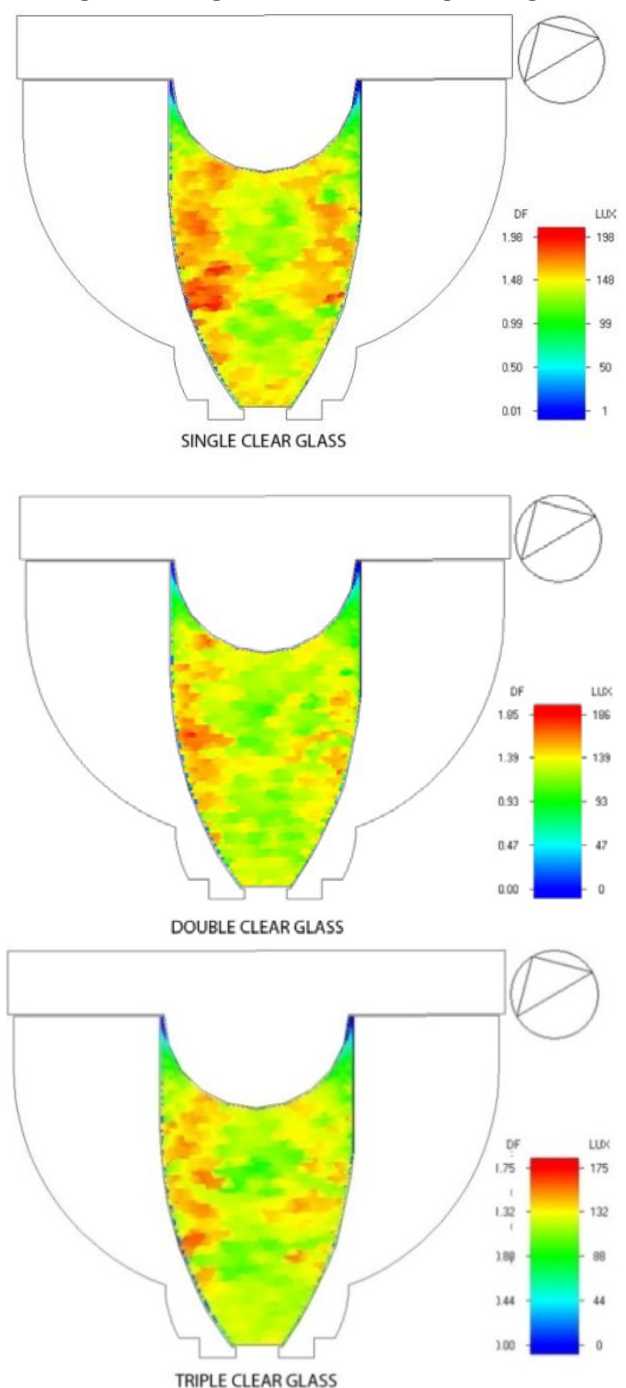

Fig. 5. Contour image of daylight delivered by multilayer clear glass.

\subsection{Clear Glass Compare to Other Glazing Technologies}

\subsubsection{Analysis of Thermal Environment}

General comparison of three coating technologies with the clear glass is shown by Figure 6. Indoor temperatures seem to be similar for all of the glazing technologies. 
Figure 6 shows that Low-e glazing technology has no impact to the indoor temperature of the atrium. More, the heat gains/losses of Low-e glazing also has no difference with the clear glass as shown by Figure 7 . This result is not as expected, since the U-value of these two materials is different. Low-e glass is expected to reduce the indoor temperature, but the prediction does not give the expected result.

The similar interpretation with the multilayer glazing can be used to explain the phenomena. The heat is trapped inside the atrium due to low U-value. However, since the direct total solar transmission through low-e glazing is much lower than clear glass, the effect of the heat trapped is abolished by small amount of heat from solar radiation.

Furthermore, low-e argon filled glazing and electrochromic glazing reduce the temperature in the atrium. Figure 6 shows the temperature reduction occurs at the same value. Glazing losses data supports the temperature data. Low-e argon filled glass and electrochromic glass gain less heat than clear glass and low-e glass. However, the temperature data shows the same reduction value although the glazing losses data shows low-e argon filled glass performs better.

The analysis can be aided by looking at properties of the two materials. The two materials, especially argon filled glass, have the lowest U-value. They also have low SHGC value. This means both materials reduce the temperature by keeping heat from outside to not entering the building instead of losing the heat from inside the building. Moreover, argon filled glass -which has lower U-value and total solar transmission than electrochromic glass- performs best for providing good thermal environment. However, this statement should be confirmed by examining the daylight performance of each glazing technology in the following discussion.

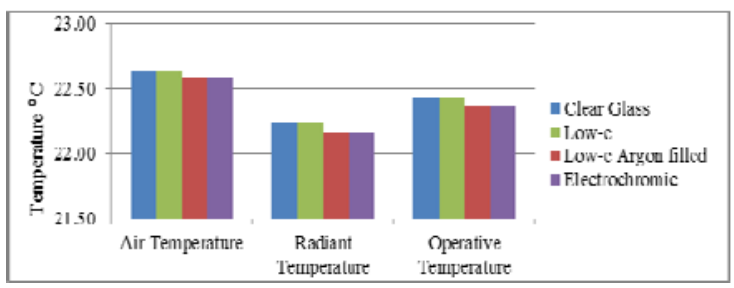

Fig. 6. Temperatures comparison resulted from different glazing technologies.

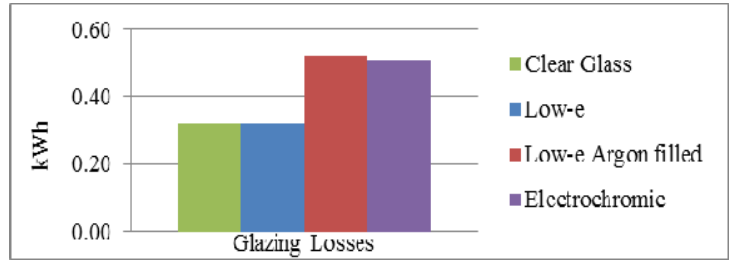

Fig. 7. Heat losses comparison of different glazing technologies.

\subsubsection{Analysis of Daylighting}

Similar with multilayer glazing, overall daylight performance meets the requirement of daylight levels from CHANNEL (2011). The average illuminances for the three materials range between 50-200 lux. Figure 8 compares daylight performance of clear glass and low-e glass. It shows that low-e glass delivers dimmer daylight. Besides, the distribution of the light is not as uniform as clear glass. The sunlight seems to be scattered by the low-e coating installed to the glazing and, it makes the light distributed inconsistently. However, its goal to reduce the incoming solar radiation -and thus reduce the temperature- is still being achieved.
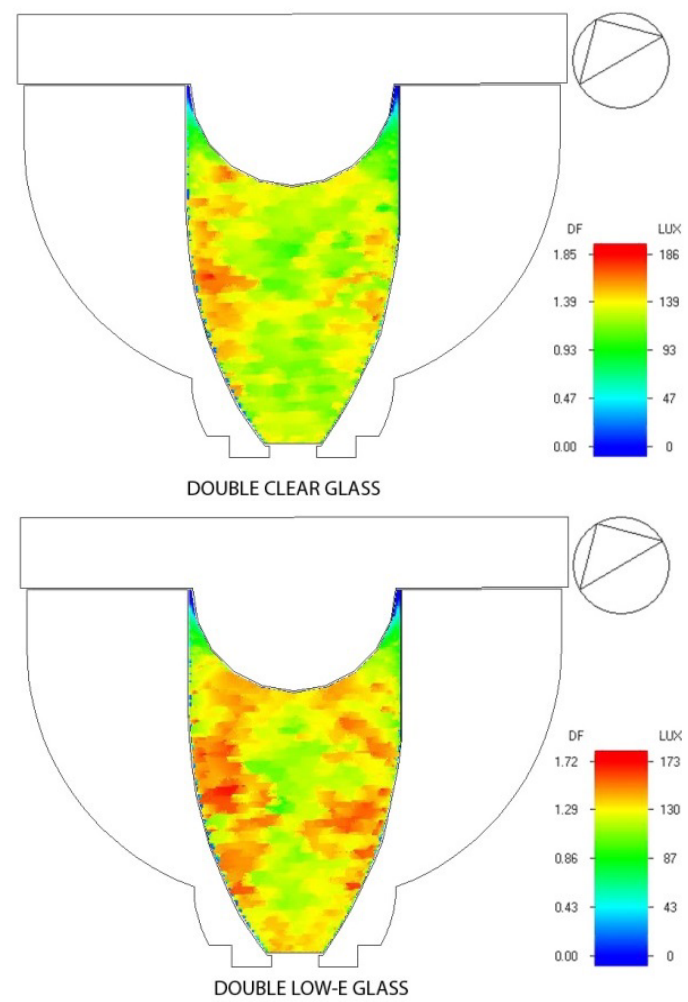

Fig. 8. Clear glass and low-e glass daylight comparison.
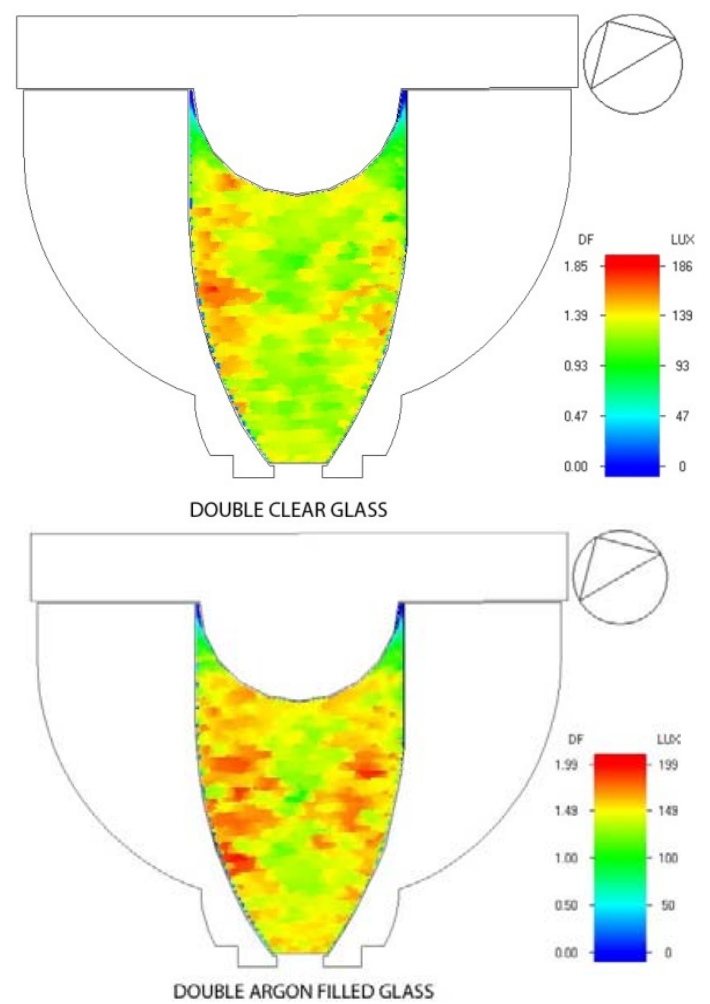

Fig. 9. Clear glass and argon-filled glass daylight comparison. 
DesignBuilder simulation for argon filled glass gives different result from low-e glazing. As shown by Figure 9, argon filled glass brings more light than clear glass and low-e glass. But, the distribution of the daylight is not as homogeneous as clear glass. However, the light delivered is still in the standard range, without any significant glare. Compare to low-e glass, daylight from argon filled glass is more preferred because it is brighter and more uniform.

Comparing electrochromic glass with the clear glass, it shows that electrochromic glass delivers brighter light. At few locations in the atrium, the daylight illuminance is even more than the range of preferred illuminance for atrium, as seen in Figure 10. Among the three glazing materials, electrochromic gives the most uniform daylight distribution. But, its illuminance is a disadvantage for electrochromic to be considered as the most appropriate material. At last, argon filled glazing performs better than the other glazing technologies. It delivers sufficient daylighting and can reduce the temperature. Furthermore, analysis of its properties supports the fact that argon filled glass is the most appropriate glazing technology.

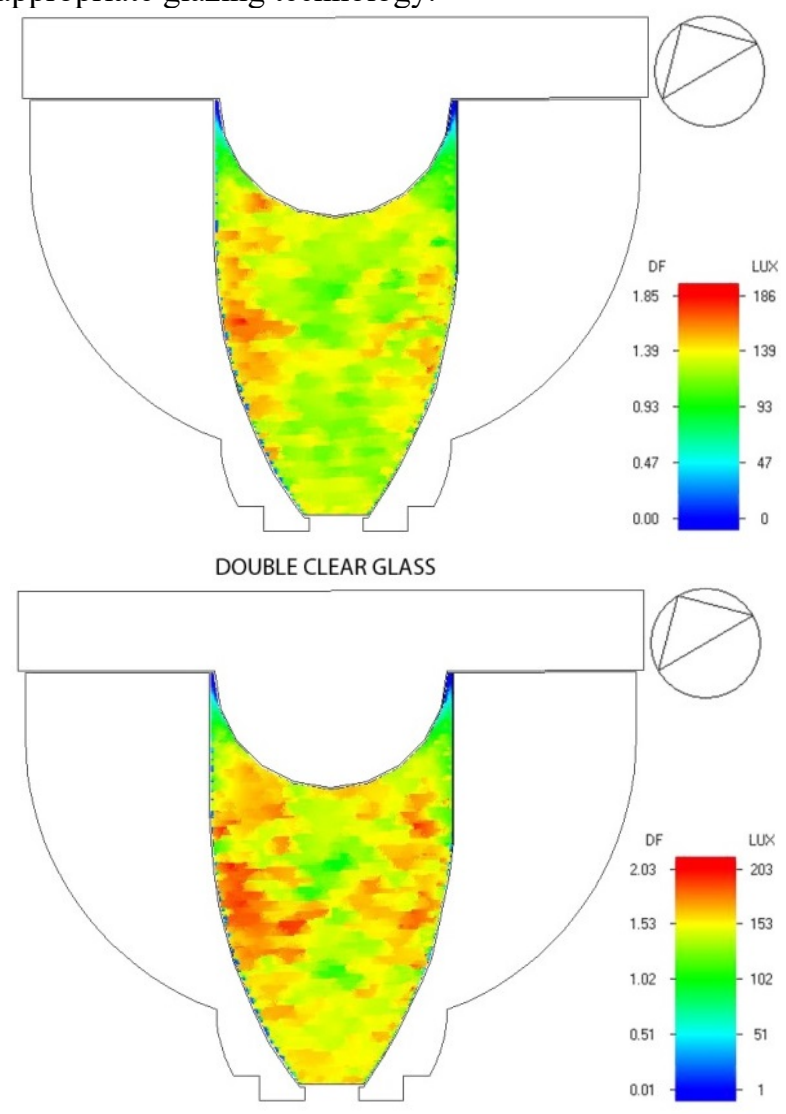

DOUBLE ELECTROCHROMIC GLASS

Fig. 10. Clear glass and electrochromic glass daylight comparison.

\section{Conclusion}

In terms of thermal performance, single glazing is in the first-rate. On the other hand, double clear glazing technology performs better than single and triple glazing in terms of daylighting performance. More glazing makes the temperature warmer because it traps the heat from inside the building. Though, this effect of increasing indoor temperature is negligible since it happens in small differences. Further, more glazing is needed to reduce light transmitted through it. Hence, triple glazing gives dimmer light than the others, although double glazing has the most uniform daylight distribution.

In addition, the analysis of performance of the other glazing technologies-low-e glass; argon filled glass; and electrochromic glass-brings out a fact that argon filled glazing technologies gain less heat than clear glass and low-e glass. argon filled glass performs better for providing good thermal environment. Argon filled glazing technology is the most appropriate for both thermal comfort and daylighting. Hence, argon filled glazing is concluded to be the most suitable material for atrium glazing in hot and humid climate.

\section{Acknowledgment}

We gratefully acknowledge the funding from USAID through the SHERA program - Centre for Development of Sustainable Region (CDSR).

\section{References}

1. P. Smealle, Building Occupant and Customer Satisfaction Survey Results for 2001, (2003)

2. M. R. Hall, Materials for Energy Efficiency and Thermal Comfort in Buildings, (2010)

3. S. Li, K. Zhong, Y. Zhou, and X. Zhang, Comparative Study on The Dynamic Heat Transfer Characteristics of PCM-filled Glass Window and Hollow Glass Window, J. Energy Build., 85, 483492, (2014)

4. E. Cuce and S. B. Riffat, A state-of-the-art review on innovative glazing technologies, Renew. Sustain. Energy Rev., 41, 695-714, (2015)

5. C.-S. Kim and S.-J. Chung, Daylighting simulation as an architectural design process in museums installed with toplights, Build. Environ., 46, 210222, (2011)

6. C. Meek and K. Van Den Wymelenberg, Daylighting and Integrated Lighting Design, (2014)

7. K. M. Al-Obaidi, M. Ismail, and A. M. A. Rahman, A study of the impact of environmental loads that penetrate a passive skylight roofing system in Malaysian buildings, Front. Archit. Res., 3, 178-191, (2014)

8. B. Ercan and S. T. Elias-Ozkan, Performance-based parametric design explorations: A method for generating appropriate building components, Des. Stud., 38, 33-53, (2015)

9. ASHRAE, ASHARE Standard 55. Thermal Environmental Conditions for Human Occupancy, $1-52,(2003)$ 
10. D. Kalz and J. Pfafferott, Thermal comfort and energy-efficient cooling of nonresidential buildings, (2014)

11. M. R. Hall and D. Allinson, Heat and Mass Transport Processes in Building Materials, in Materials for Energy Efficiency and Thermal Comfort in Buildings, (2010)

12. BRE, British Standard, (2008).
13. CHANNEL, Lighting \& Safety Systems, (2011)

14. ARCHITECTURE SG., John Portman's Singapore, (2014),

https://architecturesg.wordpress.com/2014/12/08/joh n-portmans-singapore/

15. Eastman Chemical Company, Architecture Window Films, (2013), www.iquefilms.com 